\title{
THE USE OF STANDARD METHODOLOGY FOR DETERMINATION OF ANTIFUNGAL ACTIVITY OF NATURAL PRODUCTS AGAINST MEDICAL YEASTS CANDIDA SP AND CRYPTOCOCCUS SP.
}

\author{
Liliana Scorzoni ${ }^{1}$; Tatiane Benaducci ${ }^{1}$; Ana Marisa Fusco Almeida ${ }^{1}$; Dulce Helena Siqueira Silva²; \\ Vanderlan da Silva Bolzani²; Maria José Soares Mendes Gianinni ${ }^{1 *}$
}

\begin{abstract}
${ }^{1}$ Laboratório de Micologia Clínica, Departamento de Análises Clínicas, Faculdade de Ciências Farmacêuticas, Universidade Estadual Paulista, Araraquara, São Paulo, Brasil; ${ }^{2}$ Núcleo de Bioensaios, Biossíntese e Ecofisiologia de Produtos Naturais, Departamento de Química Orgânica, Instituto de Química, Universidade Estadual Paulista, Araraquara, São Paulo, Brasil.
\end{abstract}

Submitted: January 04, 2007; Approved: July 01, 2007.

\begin{abstract}
Methodology for testing natural compounds for determination of antifungal activity had been developed with adaptations. The most used are bioautography and agar diffusion with a complex and no defined media. In this study, different methods for determination of antifungal activity of natural products are discussed and the use of M27-A2 microdilution test from CLSI (Clinical and Laboratory Standards Institute, 2002), as general standard methodology for testing plant extracts activity is recommended.
\end{abstract}

Key words: natural products, antifungal activity, Candida sp, Cryptococcus sp.

\section{INTRODUCTION}

Medicinal plants are well-known natural sources of remedies for the treatment of various diseases since the antiquity. According to a report subject by the WHO (World Health Organization), 20,000 plant species are currently in use for medicinal purposes. The use of medicinal plants in the world, and especially in South America, contributes significantly to primary health care. Plants are invaluable sources of pharmaceutical products and Brazil has supplied an incredible array of plants that has drawn the attention of ethnopharmacologists around the world. Many plants from Brazilian biomes, such as the Cerrado (savannah), the Atlantic and the Amazon rain-forests, have been used as natural medicines by local populations in the treatment of tropical diseases, including leishmaniasis, malaria, schistosomiasis, fungal and bacterial infections $(1,11)$.

Progress in isolation methods and structure elucidation has influenced an increase in the number of scientific publications dealing with pharmacological examinations of individual compounds of plant origin. Validation and selection of primary screening assays are pivotal to guarantee sound selection of extracts or molecules with relevant pharmacological action and worthy following-up. Research on new antimicrobial substances should be continued and small molecules from medicinal chemistry, as well as natural products are still major sources of innovative therapeutic agents for infectious diseases (6). Current research on natural molecules and products primarily focuses on plants since they can be sourced more easily and be selected on the basis of their ethno-medicinal use (60). Use of ethnopharmacological knowledge is one attractive way to reduce empiricism and enhance the probability of success in new drugfinding efforts (38). Many articles on natural products claim socalled "exciting" antimicrobial activities, even though major failing in the use of the methodologies. Most frequent are the lack of sound criteria for activity, the omission of appropriate in-test controls, the inclusion of unrealistically high assay dosages and the nature of the bioassay itself $(10,50)$. This is particularly true in relation to antifungal drugs. In 2001, the US National Institute for Health recommended the continuation of development of novel antifungal drugs, which belong to classes other than existing ones and possess a different mode of action.

*Corresponding Author. Mailing address: Laboratório de Micologia Clínica-Departamento de Análises Clínicas, Faculdade de Ciências Farmacêuticas, Universidade Estadual Paulista, CEP 14802-901, Araraquara, São Paulo, Brasil. E-mail: giannini@fcfar.unesp.br 
This statement was given as consequence of therapeutic limitations of most commonly used licensed antifungal drugs, the development of fungal drug resistances, drug-related toxicity, hazardous drug interactions, or insufficient bioavailability (39). Human fungal infections have increased at an alarming rate in the last 20 years, mainly among immunocompromised individuals (41)

In the last decades with the new technological discoveries and the progress of the medicine, the survival of many patients has been increasing. As consequence, we have more debilitated persons or patients with compromised immune system prone to infections, mainly caused by fungi.

New data indicate that the relative proportion of organisms causing nosocomial bloodstream infections has changed over the last decade, with Candida species now being firmly established as one of the most frequent agents. Candidemia is not only associated with a high mortality but also extends the length of hospital stay and increases the costs of medical care. Candida species are ubiquitously distributed, they reside on plants and alimentary tracts of mammals and as commensal on human mucocutaneous membranes (16). Among human gastrointestinal tract isolates $50-70 \%$ of total yeast isolates were identified as Candida albicans. Further, frequent isolates are C. tropicalis, C. parapsilosis, and C. glabrata, while C. kefyr and $C$. guilliermondii are found occasionally $(3,7,8)$.

Cryptococcus neoformans, encapsulated yeast, is the second most common cause of opportunistic fungal infection in patients with AIDS, but also cause disease in normal hosts $(15,29,56)$. Infections occur through inhalation of small diameter yeast-like organisms, which enter in the respiratory system. Therefore, the clinical manifestations of this infection can range from an asymptomatic colonization of the respiratory tract to a widespread dissemination depending on the host immune factors. As dissemination occurs, the central nervous system is commonly involved. Risk factors include: advanced HIV stage, corticosteroid use, lymphomas, solid organ transplant recipients, and patients with immune suppressive disease or receiving such drugs (24).

Some antifungal drugs, such as polyene macrolides (Amphotericin B) and azoles (Itraconazole and Fluconazole) are currently used in antifungal therapies. There is at present a question for new generations of antifungal compounds due to certain limitations like side effects as toxicity and emergence of resistant strains (57). Accessible drugs are essentially limited to the polyene natural product Amphotericin B (60) and various newer lipid formulations (20) the azole compounds such as Fluconazole and Itraconazole, and Flucytosine (5Fluorocytosine). These agents suffer from a number of limitations that can render their use complicated; for example, dose-limiting nephrotoxicity associated with Amphotericin B, rapid development of resistance with Flucytosine, drug-drug interactions, fungistatic mode of action and resistance development with the azoles. There is thus an urgent need for new antifungals with a broad fungicidal spectrum of action, and with fewer dose-limiting side effects $(17,28)$. On the other hand, since natural products have been proven to be an excellent source of drugs, we need to find out new compounds with potential antifungal activity. For that, we first must answer a simple key question: how do we identify and select a lead compound for further study, how to obtain information about the usefulness of such natural resources for development of anti-yeasts or filamentous drugs. This review discusses the available antifungal methods useful to natural products screening.

\section{OUTLINE OF STANDARD ASSAYS}

Antifungal activity of natural extracts and pure compounds can be detected by inhibition of various fungi, yeast or filamentous, by samples that are placed in contact with them. Several methods for detecting activity are available, but since they are not equally sensitive or not based upon the same principle, results will be profoundly influenced by the method. The methodology for testing natural compounds for determination of antifungal activity is variable and each research group employs different types of tests. The most used are bioautography (10), disk diffusion $(4,18)$, agar dilution $(9,37,38,55)$ and dilution tests. The general problems inherent to antifungal screening of plant extracts have already been discussed by several authours $(19,21,49)$. The correct performance, interpretation and application of the diverse methodologies will be discussed here. The antifungal test methods are classified into three main groups, i.e. diffusion, dilution and bioautographic methods. Many laboratories have modified these methods for specific samples, such as essential oils and nonpolar extracts and these modifications became impossible to directly compare results.

\section{AGAR DIFFUSION METHODS}

Agar-based disk diffusion method is appropriate because of its simplicity and low cost. This assay is based on the use of disks containing solutions of the substances to be examined, the test compound at a known concentration into contact with an inoculated medium and the diameter of the clear zone around the reservoir (inhibition diameter) is measured at the end of the incubation period. The detection limit can be elevated if the inoculated system is kept at lower temperature for several hours before incubation to favor compound diffusion over microbial growth, thereby increasing the inhibition diameter. Filter paper disks, stainless steel cylinders placed on the surface and holes punched in the medium could be used as reservoir of the test substance. To ensure that the sample does not disclose under the agar layer, fixed agar is left on the bottom of the hole. The 
possibility to test up to six extracts per plate against a single microrganism and the use of small sample volumes are specific advantages (19). The diffusion method is not appropriate for testing non-polar samples or samples that do not easily diffuse into agar. The antimicrobial potency of different samples may not always be compared, mainly because of differences in physical properties, such as solubility, volatility and diffusion characteristics in agar. Compounds having a good diffusion coefficient and low antimicrobial activity may penetrate the agar medium even in small amounts. The reverse might also hold true. This problem is encountered when zones of inhibition are compared for different classes of compounds. Additionally, size of inhibition zones might be influenced by volatilization of antimicrobial active test material, disk size, amount of compound given to disk, adsorption by the disk, agar type, agar-agar content, $\mathrm{pH}$, volume of agar, and microbial strains used. Because the absolute values of inhibition zones have only relative importance, the agar diffusion is appropriate as pre-test only and should not be used for compounds of high lipophilicity, such as volatile sesquiterpenes (39). Furthermore, agar-diffusion methods are difficult to run on high-capacity screening platforms.

The composition of the medium could influence the activity of the tested extracts. When Ross et al. (52) studied on the effects of garlic powder and garlic oil, the antimicrobial activity of garlic oil was found to be greater in media lacking tryptone or cysteine, which led to the hypothesis that the effects may involve sulfhydryl reactivity. Various growth media were used in disk diffusion test to natural products, included brain-heart infusion agar; casein-peptone soymeal-peptone agar; glucoseyeast-peptone agar; Kransky agar; malt agar; Mueller Hinton agar; Mycophil agar; nutrient agar; potato-dextrose agar; Sabouraud-dextrose agar; tryptone-yeast-glucose agar; yeastmorphology agar. Most of Candida studies with essential oils have used tryptone-yeast-glucose agar, Sabouraud-dextrose agar and potato-dextrose agar (39). The agar diffusion assay is limited to substances with considerable water solubility. Growth media and compound doses employed in this test system vary much and hamper the interpretation of results. On the other hand, the disk diffusion method was used as a laboratory routine to perform a susceptible test for licensed drugs such as fluconazole, an antifungal drug commonly used in the treatment of infections with Candida spp. There has been much research interest in agar-based antifungal susceptibility via disk diffusion method due to their relative ease and the lack of need for specialized equipment (48). RPMI 1640-glucose agar and the glucose-supplemented Mueller-Hinton agar medium were used, but the last was selected since it is specifically recommended by CLSI M44-A (33) for use in routine agar-based antifungal susceptibility testing. In our experiments, we have used RPMI 1640 with $2 \%$ of glucose and now we are developing experiments with the glucose-supplemented Mueller-Hinton agar.

\section{BIO-AUTOGRAPHY METHODS}

Antimicrobial activity can be used by bioautography that localizes on a chromatogram using three approaches: (a) direct bioautography, where the microorganism grows directly on the thin-layer-chromatographic (TLC) plate, (b) contact bioautography, where the antimicrobial compounds are transferred from the TLC plate to an inoculated agar plate through direct contact and (c) agar-overlay bioautography, where a seeded agar medium is applied directly onto the TLC plate. Despite high sensitivity, its applicability is limited to microorganisms that easily grow on TLC plates. Other problems are the need for complete removal of residual volatile solvents, such as $n-\mathrm{BuOH}$, trifluoroacetic acid and ammonia and the transfer of the active compounds from the stationary phase into the agar layer by diffusion. Because bioautography allows localizing antimicrobial activities of an extract on the chromatogram, it supports a quick search for new antimicrobial agents through bioassay-guided isolation. However, this technique is not directly applicable in current high capacity screening designs. The agar overlay bioautography method was further developed for systematic anti-candidal screening of plant extracts, which allows the identification of even small amounts of anti-microbial active compounds in complex compound mixtures. The recognition of antimicrobial activities of a compound in complex mixtures as they are obtained from crude plant extracts or essential oil distillates is the key step. TLC separation and subsequent testing of antifungal activity have been worked out for essential oils and plant extracts and led to the identification of potent anti-candidal compounds $(22,39,45)$. This method avoids the need of previous purification of the substances, reducing the costs of the initial screening. However, those are qualitative techniques and do not give data of values for Minimal Inhibitory Concentration (MIC).

\section{OTHER METHODS}

The use of standardized antifungal susceptibility methods has improved interlaboratory reproducibility. The CLSI microdilution method is labor and time-consuming and difficult to use in clinical laboratories (42). Another problem yet to be resolved is the proper interpretation of trailing growth in broth dilution MIC tests with azole antifungal agents (2). Some alternatives have emerged, including colorimetric or fluorescent methods, commercial antifungal methods and flow cytometry (FC) has been described as an excellent tool for studying the susceptibility of different microorganisms, incluing fungi (23, $43,44,46,59)$. The most advantages of FC when applied to antifungal susceptibility test follow from two different attributes of these techniques. In the first case, yields higher susceptibility and precision to the results of the tests. Second, FC assays combine the speed of cell-by-cell analysis of very large 
populations with the independence from long incubation times, resulting is faster tests. However, there are still determinant disadvantages such as: the extremely high cost of the FC equipment, remains unavailable to some researchers and slows down the process of its universal distribution to clinical laboratories. Beside that, and in spite of the evolutions made in recent times regarding the user-equipment interface, the techniques still require an experience and skilled operator in order to obtain optimal results (58).

\section{DILUTION METHODS}

In the dilution methods, the compounds are mixed with an appropriate medium that has previously been inoculated with the fungal strain. It can be carried out in liquid as well as in solid media and growth of the microorganism can be measured in a number of ways. In the agar-dilution method, the Minimal Inhibitory Concentration (MIC) is defined as the lowest concentration capable to inhibit any visible fungal growth. In liquid or broth-dilution methods, turbidity and redox-indicators are most commonly used. Turbidity can be estimated visually or achieved more accurately by measuring the optical density at $405 \mathrm{~nm}$. However, test samples that are not entirely soluble may interfere with turbidity readings, emphasizing the need for a negative control or sterility control, i.e. extract dissolved in blank medium without microorganisms. The liquid-dilution method also permits determination whether a compound or extract has a fungicidal or static action at a particular concentration. The serial dilution test yielded the best reproducible results on the MIC and was recommended as general standard methodology for testing natural products (19). Currently, the serial dilution method recommended for testing antifungal drugs to yeasts is respectively the M27A2 (32) or EUCAST (14) and to filamentous fungi, M38A from CLSI. The Clinical and Laboratory Standards Institute (CLSI; formerly the Nacional Committee for Clinical Laboratory Standards [NCCLS]) (35) had developed a standardized broth macrodilution method M27-P, National Committee For Clinical Laboratory Standards, 1992, (31) for the testing of Candida spp. and Cryptococcus neoformans which has greatly improved the reproducibility of antifungal susceptibility testing and serves as the "gold standard" by which all new methods are compared with CLSI M27-A2 (32). To increase the efficiency of testing large numbers of isolates, a broth microdilution adaptation of the reference method was developed and evaluated and gives nearly identical results $(2,12)$. In addition, the EUCAST (14) subcommittee has proposed the supplementation of the reference RPMI 1640 medium with $2 \%$ of dextrose in order to obtain a superior turbidity in the growth control well and thus shorten the MIC determination to $24 \mathrm{~h}(5,12,30,36)$. Afterwards the CLSI improved a reference method (34) National Committee for Clinical Laboratory Standards, 1997 and at this time we have the M27A2 document (32), for antifungal susceptibility testing of Candida spp. and Cryptococcus neoformans (13). The methods for yeasts are appropriate for automation and apply synthetic RPMI 1640 growth medium supplemented with $2 \%$ glucose, buffered with 3 -(N-morpholino) propanesulfonic acid, $\mathrm{pH} 7$, incubation time of $24 \mathrm{~h}$, inoculum sizes of $0.5 \times 10^{5}$ to $2.5 \times 10^{5}$ colony forming units per milliliter (CFU/ml) (32) and of 1-5 x $10^{5}$ EUCAST (14) $(\mathrm{CFU} / \mathrm{mL})$, flat-bottom microdilution trays, spectrophotometric reading, and dimethyl sulfoxide as solvent for hydrophobic compounds. Furthermore, several factors can influence the runto-run, as well as the laboratory-to-laboratory, variability of the test, including variations in the composition and $\mathrm{pH}$ of the test medium, variations in the preparation of antifungal drug dilutions, and the concentration of the inoculum (47).

Serial dilution techniques have been recommended for working with lipophilic compounds from natural products (19, 40). This technique is fully worked out, gives a link to the activity of antifungal drugs, and therefore appears to be appropriate for examining the anti-yeasts properties of plant-derived compounds in general $(25-27,54)$. The MICs obtained in RPMI 1640 medium are approximately 15 times lower than in Sabouraud dextrose broth. This fact may contribute to the difference of approximately 100-1,000 between the MICs obtained with antifungal drugs in RPMI 1640 medium and plant constituents tested in other media $(25,51,53)$.

Historically, most of the drugs are derived of natural products. Our country, due to the wide territorial extension, variety of climates and soils is privileged in biodiversity native plants, as it can be observed at the areas of the Atlantic Rain Forest and Brazilian Cerrado, also propitiating conditions for great chemical diversity of the plants of such biomes. This study was conducted as part of our ongoing bioprospecting program Biota-FAPESP that aims to discover potential antifungal compounds that could be useful for the development of new tools for the control of infectious diseases.

Initially, in our laboratory, the evaluation of the antifungal activity of the extracts and fractions containing natural products was accomplished with the disk diffusion agar method; however, this method was not sufficiently sensitive for some extracts, in spite of the formation of the halo of inhibition of the control, Amphotericin B. Those extracts were tested by the diffusion and microdilution methods; better according to the M27A2 of CLSI (32), with modifications (14). Comparing the results of both methodologies, it was observed that the diffusion agar method was less sensitive than the microdilution method. The eight extracts analyzed by micromethod presented antifungal activity, but the diffusion method was negative for the yeast Candida krusei. The microdilution method was more sensitive and we could detect the MIC, in other words, the smallest concentration showing any microbial growth inhibition; important information for the research and production of new antifungal drugs (data no showed). 
Up to now, susceptibility tests were accomplished for determination of MIC and MFC of different plants extracts, using concentrations starting from $250 \mu \mathrm{g} / \mathrm{mL}$, which are considered relevant to the research on substances for therapeutic purposes. In agreement with such data, the antifungal potential of some fractions of plants and crude extracts are promising for the search of bioactive compounds. Additionally, the minimal fungicidal concentration (MFC) could be determined by platingout samples of completely inhibited dilution cultures and assessing growth (static) or no-growth (cidal) after incubation. In agreement with our data, the use of microdilution as general standard methodology for testing plant extracts activity is recommended.

\section{ACKNOWLEDGEMENTS}

This work was funded by grants of the State of São Paulo Research Foundation (FAPESP) within the Biota-FAPESP - The Biodiversity Virtual Institute Program (www.biota.org.br) and BIOprospecTA (www.bioprospecta.org.br); Grants 98/05074-0 and 04/07932-7 awarded to VSB and DHSS, respectively. The authors acknowledge CNPq and FAPESP for research fellowships and scholarships awarded to MJSMG, VSB, DHSS and LS.

\section{RESUMO}

\section{Aplicação de metodologia padronizada para determinação da atividade antifúngica de produtos naturais contra as leveduras Candida sp and Cryptococcus sp.}

Metodologias para determinar atividade antifúngica foram desenvolvidas com adaptações para avaliar produtos naturais. As mais usadas são bioautografia e o método de difusão em agar, que empregam meios de cultura complexos, não definidos. Neste estudo são discutidos os métodos para determinação de atividade antifúngica de produtos naturais e é recomendado o uso do micrométodo modificado segundo o documento M27A2 do CLSI.

Palavras-chave: produtos naturais, atividade antifúngica, Candida sp, Cryptococcus sp.

\section{REFERENCES}

1. Alves, T.M.; Silva, A.F.; Brandao, M.; Grandi, T.S.; Smania, E.; Smania Junior A.; Zani, C.L. (2000). Biological screening of Brazilian medicinal plants. Mem. Inst. Oswaldo. Cruz, 95(3): 367-73.

2. Arthington-Skaggs, B.A.; Lee-Yang, W.; Ciblak, M.A.; Frade, J.P.; Brandt, M.E.; Hajjeh, R.A.; Harrison, L.H.; Sofair, A.N.; Warnock, D.W; Candidemia Active Surveillance Group. (2002). Comparison of visual and spectrophotometric methods of broth microdilution MIC endpoint determination and evaluation of sterol quantitation method for in vitro susceptibility testing of fluconazole and itraconazole against trailing and nontrailing Candida isolates. Antimicrob. Agents. Chemother., 46(8): 2477-81.

3. Barberino, M.G.; Silva, N.; Reboucas, C.; Barreiro, K.; Alcantara, A.P.; Netto, E. M, Albuquerque, L.; Brites, C. (2006). Evaluation of Blood Stream Infections By Candida In Three Tertiary Hospitals In Salvador, Brazil: A Case-Control Study. Braz. J. Infect Dis., 10(1): 36-40.

4. Bartner, A.; Pfeiffer, K.P.; Batner, H. (1994). Applicability of disc diffusion methods required by the pharmacopoeias for testing antibacterial activity of natural compounds. Pharmazie, 49: 512516.

5. Chryssanthou, E.; Cuenca-Estrella. M. (2002) Comparison of the Antifungal Susceptibility Testing Subcommittee of the European Committee on Antibiotic Susceptibility Testing proposed standard and the E-test with NCCLS broth microdilution method for voriconazole and caspofungin susceptibility testing of yeast species. J. Clin. Microbiol., 40(10): 3841-4.

6. Clardy, J.; Walsh, C. (2004). Lessons from natural molecules. Nature, 432(7019): 829-37.

7. Colombo, A.L.; Nucci, M.; Park, B.J.; Nouer, S.A.; Arthington-Skaggs, B.; Da Matta, D.A.; Warnock, D.; Morgan, J. Brazilian Network Candidemia Study. (2006) Epidemiology of candidemia in Brazil: a nationwide sentinel surveillance of candidemia in eleven medical centers. J. Clin. Microbiol., 44(8): 2816-23.

8. Colvard, M.D.; Cordell, G.A.; Villalobos, R.; Sancho, G.; Soejarto, D.D.; Pestle, W.; Echeverri, T.L.; Perkowitz, K.M.; Michel, J. (2006) Survey of medical ethnobotanicals for dental and oral medicine conditions and pathologies. J. Ethnopharmacol., 107(1): 134-42.

9. Cordell, G.A.; Colvard, M.D. (2005). Some thoughts on the future of ethnopharmacology. J. Ethnopharmacol., 100(1-2): 5-14.

10. Cos, P.; Vlietinck, A.J.; Berghe, D.V.; Maes, L. (2006) Anti-infective potential of natural products: how to develop a stronger in vitro 'proof-of-concept'. J. Ethnopharmacol., 106(3): 290-302.

11. Duarte, M.C.; Figueira, G.M.; Sartoratto, A.; Rehder, V.L.; Delarmelina, C. (2005). Anti-Candida activity of Brazilian medicinal plants. J. Ethnopharmacol., 97(2): 305-11

12. Espinel-Ingroff, A.; Pfaller M.A.; Messer, S.A.; Knapp, C.C.; Killian, S.; Norris, H.A.; Ghannoum, M.A. (1999). Multicenter comparison of the Sensititre YeastOne colorimetric antifungal panel with the National Committee for Clinical Laboratory Standards M27-A reference method for testing clinical isolates of common and emerging Candida spp., Cryptococcus spp., and other yeast-like organisms. J. Clin. Microbiol., 37: 591-595.

13. Espinel-Ingroff, A.; Pfaller, M.A.; Messer, S.A.; Knapp, C.C.; Holliday, N.; Killian, S. (2004). Multicenter comparison of the Sensititre YeastOne colorimetric antifungal panel with the NCCLS M27-A2 reference method for testing new antifungal agents against clinical isolates of Candida spp. J. Clin. Microbiol., 2: 718-721.

14. European Committee on Antibiotic Susceptibility. Method for determination of minimal inhibitory concentration (MIC) by broth dilution of fermentative yeasts. Discussion document EDis 7.1. (2002) Taufkirchen, Germany: European Society of Clinical Microbiology and Infectious Diseases.

15. Fusco-Almeida, A.M.; Matsumoto, M.T.; Baeza, L.C.; Oliveira R.B.S.; Kleiner, A.A.P.; Melhem M.S.C.; Mendes-Giannini M.J.S. and the Laboratory Group on Cryptococcosis. (2006). Molecular typing and antifungal susceptibility of clinical sequential isolates of Cryptococcus neoformans from Sao Paulo State, Brazil. FEMS Yeast Research (in press)

16. Goncalves, R.H.; Miranda, E.T.; Zaia, J.E.; Giannini, M.J. (2006) Species diversity of yeast in oral colonization of insulin-treated diabetes mellitus patients. Mycopathologia., 162(2):83-9.

17. Graybill, J.R. (1996). The future of antifungal therapy. Clin. Infect. Dis., Suppl 2: S166-78 
18. Gulluce, M.; Aslan, A.; Sokmen, M.; Sahin, F.; Adiguzel, A.; Agar G.; Sokmen A. (2006). Screening the antioxidant and antimicrobial properties of the lichens Parmelia saxatilis, Platismatia glauca, Ramalina pollinaria, Ramalina polymorpha and Umbilicaria nylanderiana. Phytomedicine, 13(7): 515-21

19. Hadacek, F.; Greger, H. (2000) Testing of antifungal natural products: Methodologies, comparability of results and assay of choice. Phytochem Anal, 11: 137-147.

20. Hiemenz, J.W.; Walsh, T.J. (1996). Lipid formulations of amphotericin B: recent progress and future directions. Clin. Infect. Dis., Suppl 2: S133-44.

21. Holetz, F.B.; Pessini, G.L.; Sanches, N.R.; Cortez, D.A.; Nakamura, C.V.; Filho, B.P. (2002). Screening of some plants used in the Brazilian folk medicine for the treatment of infectious diseases. Mem. Inst. Oswaldo Cruz, 97(7): 1027-31.

22. Iscan, G.; Kirimer, N.; Kurkcuoglu, M.; Baser, K.H.; Demirci, F. (2002). Antimicrobial screening of Mentha piperita essential oils. $J$. Agric. Food. Chem., 50(14): 3943-6.

23. Kirk, S.M.; Callister, S.M.; Lim, L.C.; Schell, R.F. (1997). Rapid susceptibility testing of Candida albicans by flow cytometry. J. Clin. Microbiol., 35(2): 358-63.

24. Krick, J.A. (1981). Familial cryptococcal meningitis. J. Infect Dis., 143(1): 133.

25. Larcher, G.; Morel, C.; Tronchin, G.; Landreau, A.; Seraphin, D.; Richomme, P.; Bouchara, J.P. (2004) Investigation of the antifungal activity of caledonixanthone $\mathrm{E}$ and other xanthones against Aspergillus fumigatus. Planta Med., 70(6): 569-71.

26. Lee, K.H. (1999). Anticancer drug design based on plant-derived natural products. J. Biomed. Sci., 6(4): 236-50.

27. Li, X.C.; Jacob, M.R.; Elsohly, H.N.; Nagle, D.G.; Smillie, T.J.; Walker, L.A.; Clark, A.M. (2003). Acetylenic acids inhibiting azole-resistant Candida albicans from Pentagonia gigantifolia. J. Nat. Prod., 66(8): 1132-5.

28. Maertens, J.A.; Boogaerts, M.A. (2000). Fungal cell wall inhibitors: emphasis on clinical aspects. Curr. Pharm. Des., 6(2): 225-39.

29. Matsumoto, M.T.; Fusco-Almeida, A.M.; Baeza, L.C.; Melhem, M.S.C.; Mendes-Giannini, M.J.S. (2006). Genotyping, serotyping and determination of mating-type of Cryptococcus neoformans clinical isolates from São Paulo State, Brazil. Rev. Inst. Med. Trop., São Paulo (in press).

30. Morace, G.G.; Amato, F.; Bistoni, G.; Fadda, P.; Marone, M.T.; Montagna, S.; Oliveri, L.; Polonelli, R.; Rigoli, I.; Mancuso, S.; La Face, L.; Masucci, L.; Romano, C.; Napoli, D.; Tato, M.G.; Buscema, C.M.C.; Belli, M.M.; Piccirillo, S.; Conti, S.; Covan, F.; Fanti, C.; Cavanna, F. D'Alo, Pitzurra, L. (2002). Multicenter comparative evaluation of six commercial systems and the National Committee for Clinical Laboratory Standards M27-A broth microdilution method for fluconazole susceptibility testing of Candida species. J. Clin. Microbiol., 40: 2953-2958.

31. National Committee For Clinical Laboratory Standards NCCLS. (1992). Reference method for broth dilution antifungal susceptibility testing of yeasts: proposed standard. M27-P. NCCLS. Villanova.

32. National Committee For Clinical Laboratory Standards. (2002). Reference method for broth dilution antifungal susceptibility testing of yeasts. Approved standard M27-A2, $2^{\text {nd }}$ ed. National Committee for Clinical Laboratory Standards, Wayne, $\mathrm{Pa}$.

33. National Committee for Clinical Laboratory Standards. (2004). Method for antifungal disk diffusion susceptibility testing of yeasts: approved guideline M44-A. National Committee for Clinical Laboratory Standards, Wayne, Pa.

34. National Committee for Clinical Laboratory Standards. (1997). Reference method for broth dilution antifungal susceptibility testing of yeasts. Approved standard M27-A. National Committee for Clinical Laboratory Standards; Wayne, PA.
35. National Committee For Clinical Laboratory Standards. (2002). Reference method for broth dilution antifungal susceptibility testing of filamentous fungi. Approved standard M38-A. National Committee for Clinical Laboratory Standards; Wayne, Pa.

36. Nguyen, M.H.; Yu, C.Y. (1999). Influence of incubation time, inoculum size, and glucose concentrations on spectrophotometric endpoint determinations for amphotericin B, fluconazole, and itraconazole. J. Clin. Microbiol., 37(1): 141-5.

37. Passos, X.S.; Santos, Das. C.; Ferri, P.H.; Fernandes, Ode. F.; Paula, T.F.; Garcia, A.C.; Silva, Mdo. R. (2002). Antifungal activity of Caryocar brasiliensis (Caryocaraceae) against Cryptococcus neoformans. Rev. Soc. Brás. Med. Trop., 35(6): 623-7.

38. Patwardhan, B.; Warude, D.; Pushpangadan, P.; Bhatt, N. (2005) Ayurveda and traditional Chinese medicine: a comparative overview. Evid. Based Complement. Alternat. Med., 2(4): 465-73.

39. Pauli, A. (2006). Anticandidal low molecular compounds from higher plants with special reference to compounds from essential oils. Med. Res. Rev., 26(2): 223-68.

40. Pauli, A.; Kubeczka, K.H. (1996). Evaluation of inhibitory data of essential oil constituents obtained with different microbiological testing methods. In: Franz, C.; Mathe, A.; Buchbauer, G. editors. Essential Oils: Basic and Applied Research. Carol Stream: Allured Pub. Corp., pp.33-36.

41. Perea, S.; Patterson, T.F. (2002).Antifungal resistance in pathogenic fungi. Clin. Infec. Dis., 35(9): 1073-80.

42. Pina-Vaz, C.; Costa-de-Oliveira, S.; Rodrigues, A.G.; Espinel-Ingroff, A. (2005). Comparison of two probes for testing susceptibilities of pathogenic yeasts to voriconazole, itraconazole, and caspofungin by flow cytometry. J. Clin. Microbiol., Sep. 43(9): 4674-9.

43. Pina-Vaz C.; Sansonetty, F.; Rodrigues, A.G.; Costa-de-Oliveira, S.; Martinez-de-Oliveira, J.; Fonseca, A.F. (2001). Susceptibility to fluconazole of Candida clinical isolates determined by FUN-1 staining with flow cytometry and epifluorescence microscopy. J. Med. Microbiol., 50(4): 375-82

44. Pina-Vaz, C.; Sansonetty, F.; Rodrigues, A.G.; Costa-Oliveira, S.; Tavares, C.; Martinez-de-Oliveira, J. (2001) Cytometric approach for a rapid evaluation of susceptibility of Candida strains to antifungals. Clin. Microbiol. Infect., 7(11): 609-18.

45. Rahalison, L.; Hamburger, M.; Monod, M.; Frenk, E.; Hostettmann, K. (1994). Antifungal tests in phytochemical investigations: comparison of bioautographic methods using phytopathogenic and human pathogenic fungi. Planta Med., 60(1): 41-4.

46. Ramani, R.; Chaturvedi, V. (2000). Flow cytometry antifungal susceptibility testing of pathogenic yeasts other than Candida albicans and comparison with the NCCLS broth microdilution test. Antimicrob. Agents. Chemother., 44(10): 2752-8.

47. Revankar, S.G.; Kirkpatrick, W.R.; Mcatee, R.K.; Fothergill, A.W.; Redding, S.W.; Rinaldi, M.G.; Patterson, T.F. (1998). Interpretation of trailing endpoints in antifungal susceptibility testing by the National Committee for Clinical Laboratory Standards method. J. Clin. Microbiol., 36(1): 153-6.

48. Rex, J.H.; Pfaller, M.A.; Walsh, T.J.; Chaturvedi, V.; Espinel-Ingroff, A.; Ghannoum, M.A.; Gosey, L.L.; Odds, F.C.; Rinaldi, M.G.; Sheehan, D.J.; Warnock, D.W. (2001). Antifungal susceptibility testing: practical aspects and current challenges. Clin. Microbiol. Rev., 14(4): 643-58.

49. Rios, J.L.; Recio, M.C.; Villar, A. (1988). Screening methods for natural products with antimicrobial activity: a review of the literature. J. Ethnopharmacol., 23(2-3): 127-49.

50. Rios, J.L.; Recio, M.C. (2005). Medicinal plants and antimicrobial activity. J Ethnopharmacol., 100(1-2): 80-4.

51. Romano, L.; Battaglia, F.; Masucci, L.; Sanguinetti, M.; Posteraro, B.; Plotti, G.; Zanetti, S.; Fadda, G. (2005). In vitro activity of bergamot natural essence and furocoumarin-free and distilled extracts, and their associations with boric acid, against clinical yeast isolates. J. Antimicrob Chemother., 55(1): 110-4. 
52. Ross, Z.M.; O'gara, E.A.; Hill, D.J.; Sleightholme, H.V.; Maslin, D.J. (2001). Antimicrobial properties of garlic oil against human enteric bacteria: evaluation of methodologies and comparisons with garlic oil sulfides and garlic powder, Appl. Environ. Microbiol., 67(1): 475-80.

53. Rox, B.; Rukayadi, Y.; Yong, D.; Hwang, J.K. (2006). In vitro anticandidal activity of xanthorrhizol isolated from Curcuma xanthorrhaiz. J. Antimicrob. Chemother., 57(6): 1231-4.

54. Salgueiro, L.R.; Pinto, E.; Goncalves, M.J.; Pina-Vaz, C.; Cavaleiro C.; Rodrigues, A.G.; Palmeira, A.; Tavares, C.; Costa-De-Oliveira S.; Martinez-De-Oliveira, J. (2004). Chemical composition and antifungal activity of the essential oil of Thymbra capitata. Planta Med., 70: 572.

55. Souza, L.K.; De Oliveira, C.M.; Ferri, P.H.; De Oliveira Junior, J.G.; De Souza Junior, A.H.; Fernandes, Ode. F.; Silva, Mdo. R. (2003). Antimicrobial activity of Hyptis ovalifolia towards dermatophytes. Mem. Inst. Oswaldo Cruz, 98(7): 963-5.
56. Subramanian, S.; Mathai, D. (2005). Clinical manifestations and management of cryptococcal infection. J. Postgrad. Med., 51 Suppl 1: S21-6.

57. Terrell, C.L. (1999). Antifungal agents. Part II. The azoles. Mayo Clin. Proc., 74(1): 78-100.

58. Vale-Silva, L.A.; Buchta V. (2006). Antifungal susceptibility testing by flow cytometry: is it the future? Mycoses. 49(4):261-73.

59. Wenisch, C.; Parschalk, B.; Zedwitz-Liebenstein, K.; Wernsdorfer, W.; Graninger, W. (1997).The effect of artemisinin on granulocyte function assessed by flow cytometry. J. Antimicrob. Chemother., 39(1): 99-101.

60. Wingard, R.P.; Kubilis, L. Lee.; Yee, G.M.; White, L.; Walshe, R.; Bowden, E.; Anaissie, J.; Hiemenz; Lister, J. (1999). Clinical significance of nephrotoxicity in patients treated with amphotericin B for suspected or proven aspergillosis. Clin. Infect. Dis., 29(6): 1402-7. 